\title{
Estudo anatômico comparativo da casca do caule do araçá-amarelo e araçá-vermelho, Psidium cattleianum Sabine, Myrtaceae
}

\author{
Ledyane Dalgallo Rocha ${ }^{1,2}$, Karla Heloise Preussler ${ }^{1}$, Fernanda Pegorini ${ }^{1}$, Vanessa de Farias ${ }^{1}$ e \\ Leila Teresinha Maranho ${ }^{1}$
}

Recebido em 27/09/2007. Aceito em 4/04/2008

\begin{abstract}
RESUMO - (Estudo anatômico comparativo da casca do caule do araçá-amarelo e araçá-vermelho, Psidium cattleianum Sabine, Myrtaceae). Psidium cattleianum, conhecido popularmente como araçá-amarelo e araçá-vermelho, pertence à família Myrtaceae. Esta família possui muitos problemas taxonômicos, e por este motivo, é considerada uma das mais complexas quanto à identificação de suas espécies. Com o propósito de esclarecer estas dificuldades, alguns estudos alternativos vêm sendo realizados, como a anatomia da casca, ferramenta que contribui para a compreensão de problemas taxonômicos, embora atualmente ainda seja pouco explorada. No presente estudo, a estrutura da casca caulinar do araçá-amarelo e do araçá-vermelho foi analisada, verificando se as diferenças existentes na sua anatomia correspondem à hipótese de que os mesmos se tratam de dois táxons para a espécie. Para tanto, foram coletadas amostras de três indivíduos de cada morfotipo, sendo processadas de acordo com o procedimento recomendado para análises estruturais. As diferenças entre os morfotipos podem ser observadas na periderme, no arranjo das células parenquimáticas e, de modo geral, na organização do floema colapsado. Os resultados obtidos nesta pesquisa demonstraram que os morfotipos de P. cattleianum, ainda que sejam considerados o mesmo táxon, exibem diferenças no que se refere a organização estrutural da casca do caule.
\end{abstract}

Palavras-chave: anatomia da casca, araçá, Myrtaceae, Psidium cattleianum

ABSTRACT - (Comparative anatomy study of stem bark of yellow strawberry-guava and red strawberry-guava, Psidium cattleianum Sabine, Myrtaceae). Psidium cattleianum, known as yellow strawberry-guava and red strawberry-guava, belongs to the Myrtaceae family. This family has many taxonomy problems, and for this reason, is considered one of most complicated the identification of their species. With the intention to clarify these difficulties, some alternative studies are being developed, such as the anatomy of bark, tool that contributes to the understanding of taxonomic problems; however, it is a tool currently few explored. In the present study, the structure of the stem bark of yellow strawberry-guava and red strawberry-guava was analyzed and compared, in order to verify the hypothesis of two taxons for P. cattleianum. For in such a way, samples of three individuals of each morphotypes had been collected and processed in agreement of procedure indicated for structural analyzes. The differences between the morphotypes can be observed in periderm, in the arrangement of parenchymatics cells and, in general way, in the organization of the collapsed phloem. The results gotten in this research showed that the morphotypes of $P$. cattleianum, despite they are considered the same taxon, exhibit great differences with regard to organizational structure of the stem bark.

Key words: bark anatomy, strawberry-guava, Myrtaceae, Psidium cattleianum

\section{Introdução}

Myrtaceae possui aproximadamente 4.000 espécies distribuídas em 130 gêneros e ocorre em biomas como cerrado, floresta atlântica e florestas deciduais, compondo de forma significativa a flora brasileira (Souza \& Lorenzi 2005). Apesar da ampla distribuição e importância das suas espécies, são escassos os estudos taxonômicos sobre as mesmas.

Observa-se que a morfologia de folhas e flores é muito semelhante entre as espécies de Myrtaceae e isto, por dificultar a caracterização e denominação específica, torna a família uma das mais complexas do ponto de vista taxonômico (Souza \& Lorenzi 2005). Tendo como base estas similaridades e, buscando compreender a taxonomia da família, alguns pesquisadores optaram por combinar a descrição da organização estrutural de tecidos vegetativos com as características reprodutivas, o que implicou no desenvolvimento de estudos que viabilizassem a compreensão e a caracterização sistemática de seus indivíduos.

Deste modo, iniciaram-se as pesquisas a partir de técnicas alternativas, na tentativa de fornecer informações que possam contribuir para a taxonomia de algumas

\footnotetext{
1 Universidade Positivo, Rua Professor Pedro Viriato Parigot de Souza 5300, Bairro Campo Comprido, 81280-330 Curitiba, PR, Brasil

2 Autora para correspondência: ledyane@gmail.com
} 
espécies (Landrum \& Kawasaki 1997; Souza \& Lorenzi 2005), como o estudo desenvolvido por Marchiori (1993) com o lenho de Mimosa bimucronata (DC.) Kuntze. O autor afirma que a descrição da anatomia do lenho e da casca fornece informações básicas e fundamentais.

Teixeira \& Gabrielli (2000), após descrever a anatomia de duas espécies de leguminosas, afirmam que a linha de pesquisa que envolve a anatomia do lenho encontra-se consolidada; porém, a maioria dos trabalhos trata de espécies exóticas utilizadas em reflorestamentos e de interesse econômico. Dentro desta perspectiva, verifica-se a necessidade de investimento em estudos voltados para a descrição da anatomia da madeira e casca de espécies nativas, como fizeram Pollito \& Tomazello (2006) para duas espécies de Uncaria Schreb. Neste estudo, os autores relatam que a avaliação destes tecidos permite a identificação de espécies de, tanto em laboratório como em campo.

Atualmente, observa-se uma terminologia variada para se referir aos constituintes da casca. Richter et al. (1996) que estabeleceram uma padronização de critérios para a sua descrição, definem casca como um conjunto de tecidos localizados externamente ao câmbio vascular e que está presente em plantas com crescimento secundário.

Psidium L. pertence à tribo Myrteae e subtribo Pimentoideae (Flora Brasiliensis 2006). Dentre as espécies nativas do Brasil está Psidium cattleianum Sabine que recebe, de acordo com Lorenzi (1992), as denominações populares de araçá, araçá-amarelo, araçávermelho, china-guava e, segundo Backes \& Nardino (2004), araçazeiro-amarelo e araçazeiro-vermelho. No Brasil, P. cattleianum ocorre do Estado da Bahia até o Rio Grande do Sul, em restingas litorâneas, locais úmidos de um modo geral, na Floresta Ombrófila Densa e raramente na Depressão Central. Trata-se de uma espécie arbórea cuja altura varia entre 3,0 e 6,0 m, com tronco liso e casca descamante (Lorenzi 1992). Os frutos são amarelos ou vermelhos (Lorenzi 1992), o que sugere que a espécie possa ser dividida em dois morfotipos denominados araçá-amarelo e araçá-vermelho.

Psidium cattleianum possui atualmente diferentes denominações taxonômicas específicas e, de acordo com estudos preliminares, isto se deve ao fato de não haver consenso entre os especialistas, além de que as categorizações não são utilizadas no momento das determinações. Análises prévias indicaram que ocorrem diferenças na anatomia do lenho, na morfologia foliar e na coloração dos frutos dos dois grupos de P. cattleianum. Assim, levantou-se a hipótese de que os morfotipos se tratam de táxons diferentes para a espécie.

Com base nisto, o objetivo do presente estudo foi analisar a estrutura da casca caulinar do araçá-vermelho e do araçá-amarelo, verificando se as diferenças existentes correspondem à hipótese levantada acima.

\section{Material e métodos}

A coleta das amostras foi realizada em um remanescente florestal localizado no bairro Umbará, região Sul de Curitiba, Paraná, Brasil, entre as coordenadas geográficas $25^{\circ} 35^{\prime} 1,2^{\prime \prime} \mathrm{S}$ e $49^{\circ} 15^{\prime} 43,7^{\prime \prime} \mathrm{W}$. Selecionaram-se três indivíduos de cada morfotipo e de cada um foi coletado um disco de um ramo secundário para preservar a integridade da planta. As secções foram feitas à altura do peito (AP), obtendo-se discos de 3,0-6,0 cm de diâmetro e 4,0 cm de espessura. A fixação das amostras foi feita mediante o emprego de FAA 70 por 48 horas (Johansen 1940) e, posterior armazenamento em etanol 70\% (Berlyn \& Miksche 1976).

Para o preparo das lâminas permanentes retiraramse nove amostras de cada disco, as quais foram incluídas em glicolmetacrilato (JB-4), de acordo com o procedimento descrito por Feder \& O'Brien (1968), seguindo as especificações do fabricante (Polysciences Inc.). De cada indivíduo foram orientadas três amostras no sentido longitudinal tangencial, três no sentido longitudinal radial e três no sentido transversal, totalizando 27 amostras de cada morfotipo. O seccionamento foi realizado em micrótomo de rotação (Leica RM2125) com espessura de $7 \mu \mathrm{m}$, a coloração com azul de toluidina $0,05 \%$ (Sakai 1973) e a montagem com a resina sintética Entellan ${ }^{\circledR}$.

Para obtenção das ilustrações e escalas, assim como para a descrição das secções e mensurações empregouse o microscópio fotônico (Olympus - CX41RF) acoplado à câmara clara com ocular micrométrica e o fotomicroscópio (Olympus - BX 41) com o software Image ProPlus.

As mensurações e a contagem de camadas celulares foram feitas totalizando-se 54 amostragens de cada morfotipo por caractere, obtendo-se, posteriormente as médias e os respectivos desvios padrões. As descrições da casca dos dois morfotipos obedeceram às recomendações de Trockenbrodt (1990); Junikka (1994) e Richter et al. (1996).

\section{Resultados}

As cascas caulinares do morfotipo amarelo e vermelho apresentam-se compostas por ritidoma, periderme, floema colapsado e floema não colapsado (Fig. 1, 2).

Em ambos os morfotipos o ritidoma é o tecido mais externo da casca do caule (Fig. 1, 2) (Tab.1). Esta estrutura é formada por peridermes seqüenciais e tecidos 


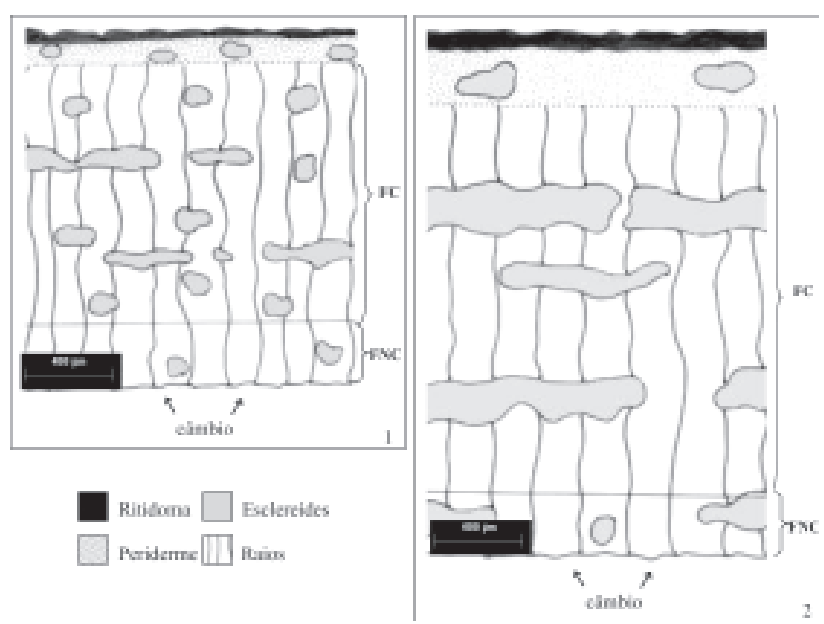

Figuras 1-2. Diagramas da casca caulinar de Psidium cattleianum Sabine em secções transversais. 1. Morfotipo amarelo. 2. Morfotipo vermelho. (FC: floema colapsado; FNC: floema não colapsado).

por elas englobados. Subjacente ao ritidoma encontrase a periderme (Fig. 1-4), a qual é constituída por felema, felogênio e feloderme.

A periderme mostra-se mais espessa no morfotipo vermelho (Tab.1). O felema é composto por células alongadas radialmente (Fig. 1-4) e que se caracterizam pela ocorrência de um conteúdo acastanhado. No morfotipo amarelo o felema possui de 7-10 camadas de células e, no morfotipo vermelho de 9-11 (Fig. 3, 4).

Tanto no morfotipo amarelo como no vermelho, o felogênio é formado por células irregulares, achatadas radialmente, alongadas no sentido transversal e com paredes celulares delgadas. A feloderme é composta por camadas celulares dispostas radialmente na mesma fileira das células do felema (Fig. 3, 4). Internamente à periderme, inicia-se o floema colapsado (Tab. 1), cuja espessura é maior no morfotipo vermelho. Em ambos os morfotipos, o floema colapsado é composto por células parenquimáticas e elementos de tubo crivado (Fig. 1-4) e as esclereídes dispõem-se isoladamente ou em grupos entre as células floemáticas (Fig. 3-6).

As esclereídes, quando observadas na secção radial, apresentam-se em faixas longitudinais tangenciais, assim como as fibras septadas. Esta disposição é desorganizada e irregular no morfotipo amarelo, pois as faixas possuem largura e altura variadas (Fig. 1, 3, 7); no morfotipo vermelho formam faixas contínuas que tende a apresentar larguras semelhantes em toda a extensão do floema colapsado. Esta organização confere um arranjo definido ao esclerênquima observado no morfotipo vermelho (Fig. 2, 8) (Tab. 1). Em secção transversal, pode-se observar que as esclereídes, de ambos os morfotipos, possuem paredes celulares polilameladas e pontoações simples (Fig. 9, 10).

As células de parênquima radial estão logo após a feloderme e, a organização do parênquima radial e axial, descarta a existência de pseudocórtex em ambos os morfotipos (Fig. 1-4). Observam-se raios uni ou bisseriados e heterogêneos constituídos por células eretas e quadradas, quadradas e procumbentes, ou ainda, eretas e procumbentes (Fig. 11-14).

A maioria dos raios observados no morfotipo amarelo apresenta-se constituída por células marginais eretas e corpo do raio formado por 4-6 células quadradas (Fig. 11). Os raios observados no morfotipo vermelho, em geral, estão formados por células marginais eretas,

Tabela 1. Características anatômicas das cascas caulinares dos dois morfotipos de Psidium cattleianum Sabine ( \pm : desvio padrão).

\begin{tabular}{lcc}
\hline Caracteres & Morfotipo amarelo & Morfotipo vermelho \\
\hline Espessuras $(\mu \mathrm{m})$ : & & $60,25 \pm 1,22$ \\
$\quad$ Ritidoma & $57 \pm 2,24$ & $276,25 \pm 1,50$ \\
Periderme & $143,50 \pm 1,18$ & $2129 \pm 2,44$ \\
Floema colapsado & $1656 \pm 1,78$ & $345,75 \pm 2,45$ \\
Floema não colapsado & $364,25 \pm 1,38$ & $140,02 \pm 0,83$ \\
Elemento de tubo crivado: & & $25,87 \pm 1,92$ \\
Comprimento $(\mu \mathrm{m})$ & $137,08 \pm 2,48$ & $152^{\circ} \pm 0,57$ \\
Diâmetro $(\mu \mathrm{m})$ & $24,28 \pm 1,41$ & Marginais eretas, corpo do \\
Ângulo de inclinação da placa crivada & $159^{\circ} \pm 0,81$ & procumbentes \\
Raio: & & $272,40 \pm 1,99$ \\
Composição celular & Marginais eretas, corpo do formado por células quadradas e \\
& raio formado por células quadradas. & $212,20 \pm 9,17$ \\
Altura $(\mu \mathrm{m})$ & $221,80 \pm 13,94$ & faixas tangenciais com tamanhos semelhantes \\
Largura $(\mu \mathrm{m})$ & $191,10 \pm 2,54$ & Em torno do raio organizado; \\
Série cristalífera & Em um dos lados do raio & \\
Arranjo do esclerênquima & desorganizado; grupos ou faixas & \\
\hline
\end{tabular}



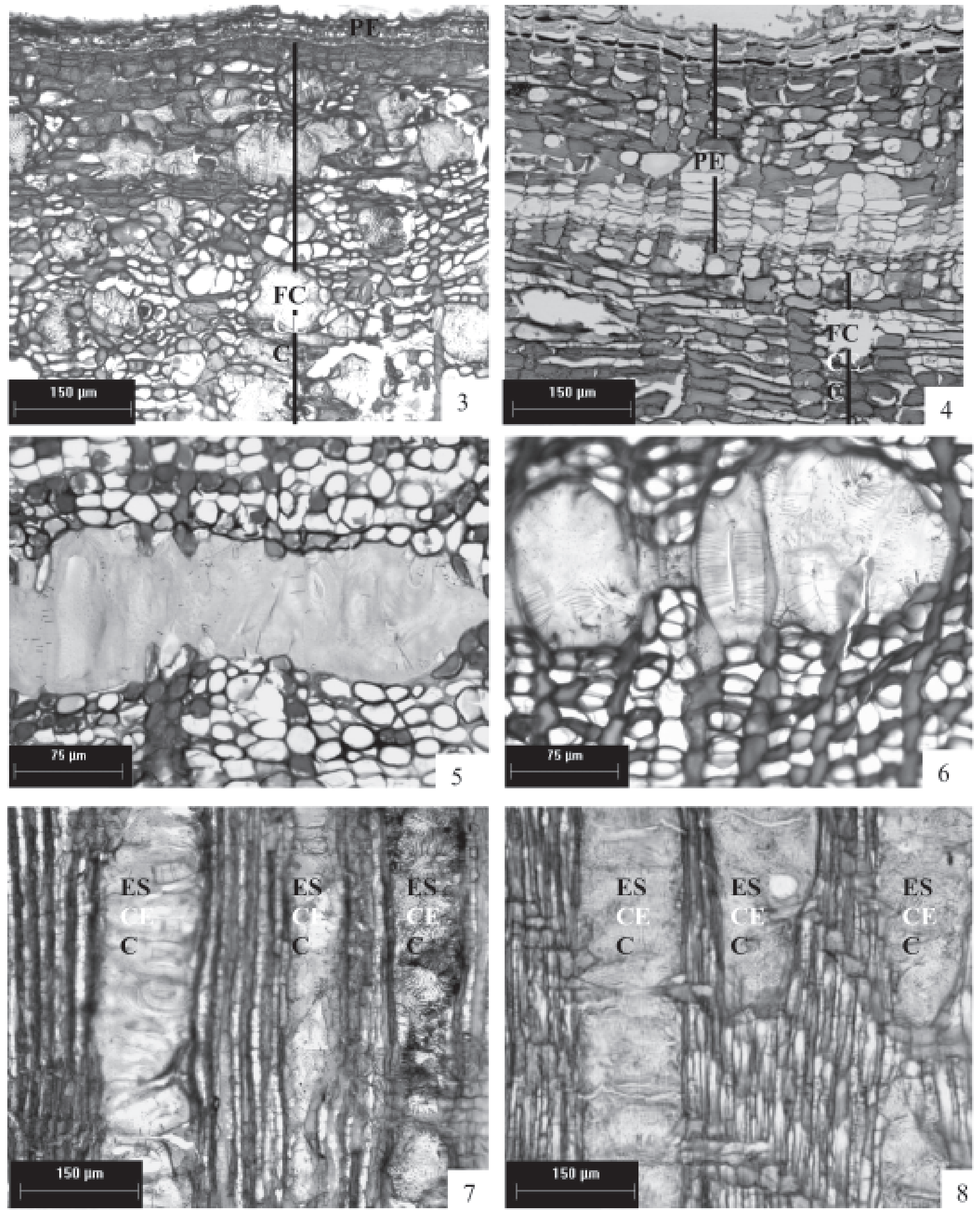

Figuras 3-8. Secções da casca de Psidium cattleianum Sabine. 3-4. Periderme e floema colapsado em secção transversal. 3. Morfotipo amarelo. 4. Morfotipo vermelho. 5-6. Grupos de esclereídes em secção transversal. 5. Morfotipo amarelo. 6. Morfotipo vermelho. 7-8. Disposição das esclereídes em secção longitudinal do morfotipo amarelo e vermelho respectivamente. (PE: periderme; FC: floema colapsado; ES: esclereídes). 

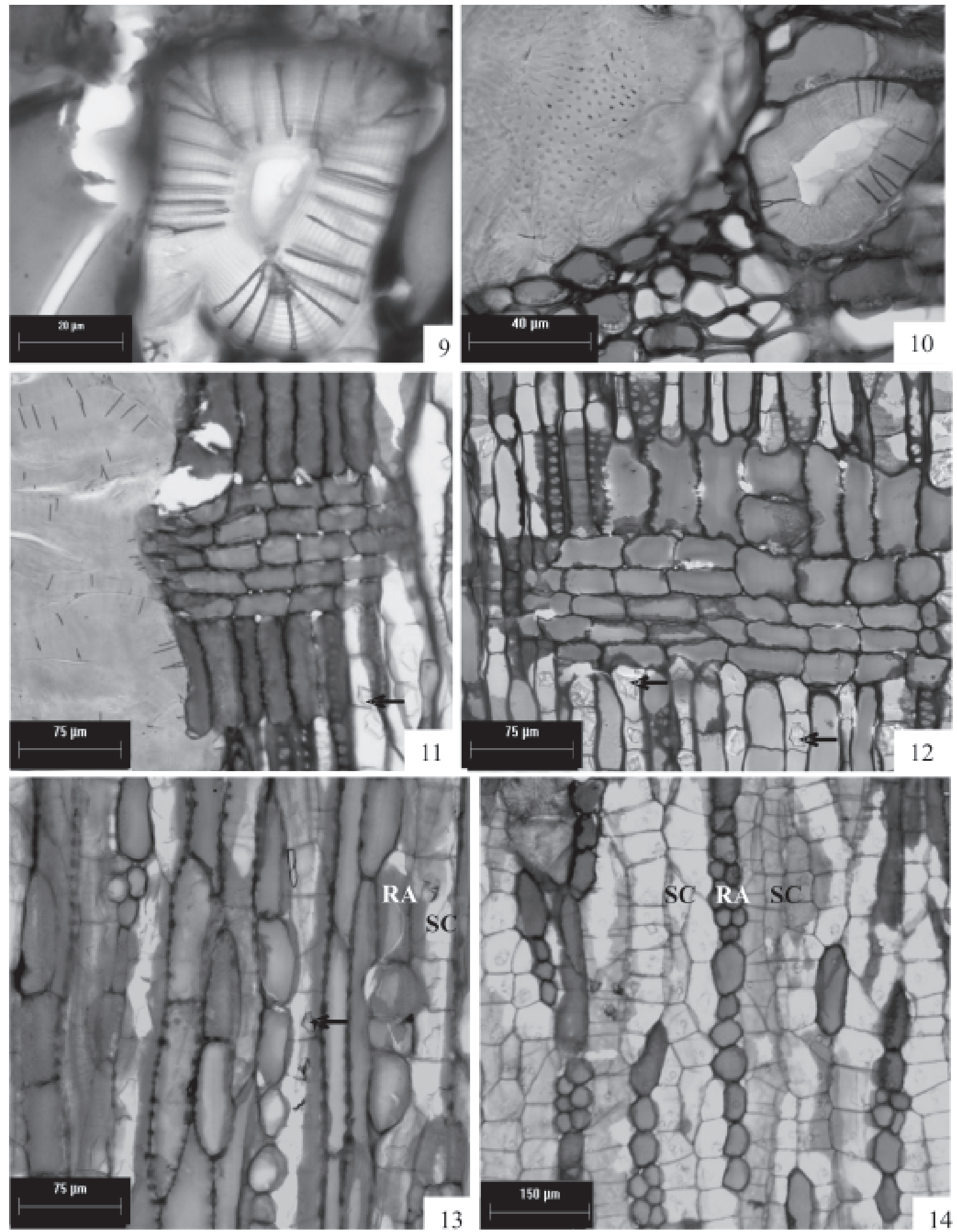

Figuras 9-14. Secções da casca de Psidium cattleianum Sabine. 9-10. Secções transversais das esclereídes (detalhe das paredes polilameladas e pontoações simples). 11-12. Secções longitudinais radiais demonstrando a constituição celular dos raios no morfotipos amarelo e vermelho respectivamente. 13. Detalhe da série cristalífera em um dos lados do raio no morfotipo amarelo. 14. Detalhe da série cristalífera envolvendo todo o raio do morfotipo vermelho. (setas para a esquerda $(\leftarrow)$ : cristais prismáticos; SC: série cristalífera; RA: raio). 
sendo estas seguidas por células quadradas e, internamente a elas, encontram-se células procumbentes formando o corpo do raio. Uma das fileiras marginais de células eretas pode estar ausente (Fig. 12).

Os raios dos morfotipos diferem em tamanho, ainda que, em ambos, o parênquima radial não possua dilatação (Fig. 3, 4). O desvio padrão foi maior para a altura dos raios no morfotipo amarelo e para a largura dos mesmos no morfotipo vermelho (Tab. 1).

As séries cristalíferas são formadas por células contendo um cristal prismático no seu interior e apresentam-se orientadas axial e radialmente. Em secção longitudinal tangencial, observa-se que estas séries se encontram somente em um dos lados do raio no morfotipo amarelo (Fig. 13), ao passo que no morfotipo vermelho as séries cristalíferas envolvem cada um dos raios (Fig. 14).

Em secção transversal observa-se parênquima axial formado por células de formatos variados, esclereídes, fibras e elementos de tubo crivado (Tab. 1) com suas respectivas células companheiras (Fig. 15, 16). Em ambos os morfotipos, os elementos de tubo crivado encontram-se colapsados em função da deposição de calose. As áreas crivadas são escalariformes e as placas crivadas são oblíquas e simples, encontrando-se mais inclinadas no morfotipo amarelo (Tab. 1) (Fig. 17-20).

Nos morfotipos de $P$. cattleianum o floema não colapsado (Tab. 1) caracteriza-se principalmente pela ocorrência de células parenquimáticas com paredes delgadas e células condutoras ativas. $\mathrm{O}$ esclerênquima diminui sua ocorrência conforme se aproxima ao câmbio vascular, podendo-se observar apenas algumas esclereídes solitárias (Fig. 1, 2, 21). É freqüente a ocorrência de cristais no interior de células do parênquima floemático (Fig. 22). Na região próxima ao câmbio vascular, os elementos de tubo crivado possuem placas e áreas crivadas não colapsadas, e as pontoações são bem definidas e visíveis. Observam-se grãos de amido no interior das células parenquimáticas e o arranjo das mesmas é semelhante aquele observado no floema colapsado (Fig. 22).

\section{Discussão}

No presente estudo verificou-se que a análise comparativa da organização estrutural dos tecidos que compõem a casca caulinar de $P$. cattleianum é uma ferramenta que propiciou a obtenção de diferenças entre os morfotipos amarelo e vermelho. Algumas das características obtidas possuem relevância taxonômica de acordo com Chattaway (1952), Roth (1981), Marchiori (1993), Marchiori (1996), Soffiatti \&
Angyalossy-Alfonso (1999), Castro et al. (2006) e Pollito \& Tomazello (2006).

A casca do caule de ambos os morfotipos de $P$. cattleianum apresenta cristais prismáticos em abundância por toda a região floemática, porém, o morfotipo amarelo possui cristais em maior quantidade. Roth (1981) afirma que a formação de cristais no floema ocorre em vários grupos que apresentam crescimento secundário. Em $P$. cattleianum, cristais prismáticos são freqüentes no floema, e se encontram em maior quantidade no floema colapsado, corroborando com Roth (1981). A autora ainda relata que os cristais são freqüentes no floema colapsado e a sua formação tem relação com a esclerificação. Todavia, esta informação não deve ser generalizada, uma vez que Soffiatti \& AngyalossyAlfonso (1999), observaram cristais por toda a região entre a periderme e o câmbio vascular em espécies do gênero Eugenia L.

De acordo com Roth (1981), Metcalfe \& Chalk (1983) e Dias-Leme et al. (1995) a distribuição das séries cristalíferas é importante taxonomicamente. Segundo Roth (1981), em Myrtaceae, estas séries contribuem para o diagnóstico distintivo. Em P. cattleianum as séries cristalíferas ocorrem juntamente com os raios parenquimáticos no floema e, ainda que os cristais tenham formato semelhante, a distribuição das mesmas é distinta entre os morfotipos.

Dentre os estudos sobre a anatomia da casca do caule que consideraram a presença das séries cristalíferas em espécies de Myrtaceae, está o de Soffiatti \& Angyalossy-Alfonso (1999), no qual as espécies de Eugenia analisadas possuem séries cristalíferas por todo o parênquima axial. Fabrowski et al. (2003) observaram as séries cristalíferas no floema não colapsado de Eucalyptus smithii (RT.) Baker, tal como pode ser verificado em $P$. cattleianum.

Nos morfotipos de $P$. cattleianum o tecido floemático, de um modo geral, apresenta-se melhor organizado e uniforme no morfotipo vermelho e, desorganizado e irregular no morfotipo amarelo. Inoue \& Reissman (1971) afirmam que o floema não colapsado, por não sofrer influência do meio ambiente, serve como elemento rigoroso de caracterização de espécies. Além disto, Détienne \& Jacquet (1983), Soffiatti \& Angyalossy-Alfonso (1999) e Castro et al. (2006) relatam que o arranjo das células do floema auxilia a taxonomia de alguns grupos.

Estudos realizados com espécies pertencentes às famílias Podocarpaceae, Araucariaceae e Mimosaceae, revelaram que a morfologia externa e $\mathrm{o}$ arranjo das células que constituem o parênquima axial são características que podem ser utilizadas na identificação de espécies no momento em que as estruturas reprodutivas da planta 

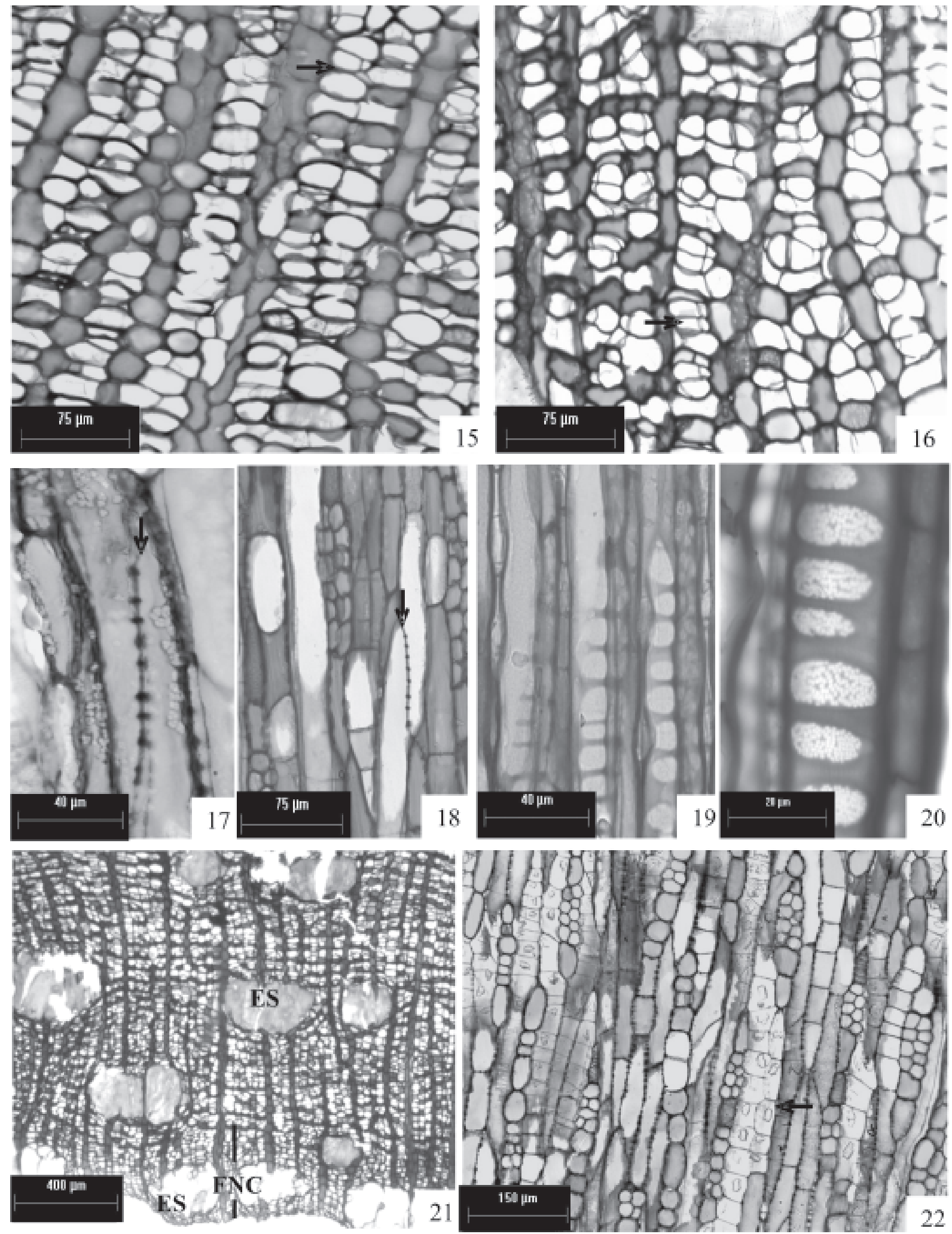

Figuras 15-22. Secções da casca de Psidium cattleianum Sabine. 15-16. Floema colapsado em secção transversal do morfotipo amarelo e vermelho, respectivamente. 17-18. Placas crivadas oblíquas em secção longitudinal tangencial dos morfotipos amarelo e vermelho respectivamente. 19-20. Áreas crivadas escalariformes. 21. Arranjo do floema não colapsado em ambos os morfotipos. 22. Secção longitudinal tangencial do floema não colapsado demonstrando o arranjo dos parênquimas axial e radial em ambos os morfotipos. (setas para a direita $(\rightarrow)$ : elementos de tubo crivado e células companheiras; setas para baixo $(\downarrow)$ : placas crivadas oblíquas; setas para a esquerda $(\leftarrow)$ : cristais prismáticos; setas para cima (१): esclereídes; ES: esclereídes; FNC: floema não colapsado). 
faltarem (Marchiori 1996; Castro et al. 2006).

Roth (1977) verificou que o floema pode ser semelhante em indivíduos da sub-família em que está incluído o gênero Mimosa. Mais tarde, Marchiori (1993), pela realização da descrição da organização estrutural do lenho e casca de Mimosa bimucronata, obteve informações que podem servir como parâmetros distintivos desta espécie.

Estudos sobre a anatomia da casca caulinar permitiram esclarecer questões evolutivas, taxonômicas e ecológicas. A compreensão da organização estrutural da casca do caule fornece informações que superam aquelas que são obtidas após a análise do lenho (Soffiatti \& Angyalossy-Alfonso 1999). Assim, verifica-se a importância do conhecimento dos caracteres morfológicos da casca, tendo em vista a precisão e conseqüente relevância dos dados resultantes da sua descrição (Chattaway 1952; Marchiori 1993; Soffiatti \& Angyalossy-Alfonso 1999; Pollito \& Tomazello 2006; Castro et al. 2006).

Apesar da importância, verifica-se pouco investimento no estudo da casca para segregação taxonômica (Chattaway 1952) tendo em vista que a literatura não abrange um grande número de espécies e tão pouco é explorada (Marchiori 1993). Adicionalmente, é de suma relevância que estudos deste cunho sejam realizados com espécies nativas, pois o conhecimento destes aspectos é ainda incipiente para os componentes da flora brasileira (Maranho et al. 2006).

A taxonomia de alguns grupos também foi esclarecida através da análise da estrutura do lenho (Maranho et al. 2006), como algumas espécies pertencentes à família Lauraceae (Oliveira et al. 2001). Teixeira \& Gabrielli (2000), no entanto, afirmam que os dados obtidos a partir da análise xilemática podem ser semelhantes para muitas espécies e que, devido a isto, não devem ser o único parâmetro para a segregação taxonômica.

Pelo exposto, observa-se que estudos com a anatomia comparativa da casca do caule vêm contribuindo consideravelmente para a segregação de espécies, pois as características obtidas são bastante peculiares e servem de base para as categorizações. Além da anatomia, outras linhas de pesquisas vêm se consolidando na família Myrtaceae, como as chaves de identificação construídas por Landrum \& Kawasaki (1997) a partir de avaliações cromossomáticas. Estas chaves forneceram cacteres que são considerados parâmetros sistemáticos na família.

Soffiatti e Angyalossy-Alfonso (1999) afirmam que, para as espécies de Eugenia estudadas, a anatomia da casca caulinar foi importante para a segregação das mesmas, pois o lenho destes vegetais coincide em vários aspectos. A casca, por outro lado, exibiu diferenças capazes de caracterizar as espécies. Este mesmo fato pode ser verificado nos dois morfotipos de $P$. cattleianum, pois a obtenção de dados distintos só tornou-se possível após a análise comparativa da estrutura da casca caulinar, visto que estudos preliminares demonstraram que o lenho dos morfotipos não apresenta diferenças.

Os resultados obtidos nesta pesquisa demonstram que os morfotipos de $P$. cattleianum, ainda que sejam considerados o mesmo táxon, apresentam diferenças consideráveis no que se refere à organização estrutural da casca do caule. Foi possível verificar que cada morfotipo exibe características particulares e estas possuem relevância taxonômica.

A realização deste trabalho permitiu ampliar a literatura sobre a anatomia da casca caulinar, demonstrando sua importância frente à taxonomia vegetal. Além disto, fomentam-se estudos com a organização estrutural da casca, uma vez que se tornou possível a obtenção de subsídios capazes de auxiliar a categorização de $P$. cattleianum, bem como a taxonomia da família Myrtaceae.

\section{Agradecimentos}

As autoras agradecem à Universidade Positivo, Curso de Ciências Biológicas e Mestrado Profissional em Gestão Ambiental.

\section{Referências bibliográficas}

Backes, A. \& Nardino, M. 2004. Nomes populares e científicos de plantas do Rio Grande do Sul. 2.ed. São Leopoldo, Ed. Unisinos. Berlyn, G.P. \& Miksche, J.P. 1976. Botanical microtechnique and cytochemistry. Iowa, Iowa University.

Castro, M.A.; Apóstolo, N.M. \& Navarro, L.E. 2006. Bark anatomy of three indigenous conifers from southern South America. Australian Journal of Botany 54: 73-82.

Chattaway, M.M. 1952. The anatomy of bark. I. The genus Eucalyptus. Australian Journal of Botany 1: 402-433.

Dias-Leme, C.L.; Gasson, P. \& Lughada, E.N. 1995. Wood anatomy of four Myrtaceae genera in the subtribe Myrciinae from South América. IAWA Journal 16: 87-95.

Détienne, P. \& Jacquet, P. 1983. Atlas d'identification des bois de l'amazonie et des régions voisines. Nogent-sur-Marne, Centre Technique Forestier Tropical.

Fabrowski, F.J.; Muñiz, G.I.B.; Nakashima, T.; Nisgoski, S. \& Klock, U.N.U. 2003. Investigação da presença de óleo essencial em Eucalyptus smithii R.T. Baker por meio da anatomia de seu lenho e casca. Ciência Florestal 13: 95-106.

Feder, N. \& O’Brien, T.P. 1968. Plant microthecnique - some principles and new methods. American Journal of Botany 55: $123-142$.

Flora Brasiliensis. 2006. Família Myrtaceae: classificação segundo a Flora Brasiliensis. Disponível em: http://florabrasiliensis.cria.org.br/ search?taxon_id=2882. (Acesso em: 26/10/2006).

Inoue, M.T. \& Reissman, C.T. 1971. Terminologia dendrológica para árvores nativas do Brasil. Revista Floresta 3: 12-15. 
Johansen, D.A. 1940. Plant microtechnique. New York, Mc Graw Hill Book.

Junikka, L. 1994. Survey of English macroscopic barck terminology. IAWA Journal 15: 3-45.

Landrum, L.R. \& Kawasaki, M.L. 1997. The genera of Myrtaceae in Brazil: an ilustred synopitic treatment and identification keys. Brittonia 49: 508-536.

Lorenzi, H. 1992. Árvores brasileiras (manual de identificação e cultivo de plantas arbóreas nativas do Brasil). Nova Odessa, Instituto Plantarum.

Maranho, L.T.; Galvão, F.; Muniz, G.I.B.; Kuniyoshi, Y.S. \& Preussler, K.H. 2006. Variação dimensional das traqueídes ao longo do caule de Podocarpus lambertii Klotzsch ex Endl. Podocarpaceae. Acta Botanica Brasilica 20: 633-640.

Marchiori, J.N.C. 1993. Anatomia da madeira e casca do Maricá, Mimosa bimucronata (DC.) O. Kuntze. Ciência Florestal 3: 85-106.

Marchiori, J.N.C. 1996. Anatomia do xilema secundário de Mimosa incana (Spreng.) Benth. Ciência Florestal 6: 53-63.

Metcalfe, C.R. \& Chalk, L. 1983. Anatomy of the dicotyledons. Vol. II. Wood structure and conclusion of the general introduction. $2^{\text {nd }}$ ed. Oxford, Clarendon Press.

Oliveira, C.W.; Callado, C.H. \& Marquete, O. 2001. Anatomia do lenho de espécies do gênero Nectandra Rol. ex Rottb. (Lauraceae). Rodriguésia 52: 125-134.

Pollito, P.A.Z. \& Tomazello, M. 2006. Anatomia do lenho de Uncaria guianensis e U. tomentosa (Rubiaceae) do Estado do Acre, Brasil. Acta Amazonica 36: 169-176.
Richter, H.G.; Mazzoni-Viveiros, S.C.; Alves, E.S.; Luchi, A.E. \& Costa, C.G. 1996. Padronização de critérios para a descrição anatômica da casca: lista de características e glossário de termos. Revista do Instituto Florestal e IF Série Registros 16:1-25.

Roth, I. 1977. Estructura anatomica de la corteza de algunas espécies arboreas venezolanas de Mimosaceae. Acta Botanica Venezuelica 12: 293-355.

Roth, I. 1981. Structural patterns of tropical barks. Berlin, Gebrüder Borntraeger.

Sakai, W.S. 1973. Simple method for differentialstaining of parafin embedded plant material using toluidine blue. Stain Technology 48: 247-249.

Soffiatti, P. \& Angyalossy-Alfonso, V. 1999. Estudo anatômico comparativo do lenho e da casca de duas espécies de Eugenia L. (Myrtaceae). Revista Brasileira de Botânica 22: 175-184.

Souza, V.C. \& Lorenzi, H. 2005. Botânica sistemática (guia ilustrado para identificação das famílias de Angiospermaas da flora brasileira, baseado em APG II). Nova Odessa, Instituto Plantarum

Teixeira, S.P. \& Gabrielli, A.C. 2000. Anatomia do eixo vegetativo de Dahlstedtia pinnata (Benth.) Malme e D. pentaphylla (Taub.) Burk. (Leguminosae, Papilionoideae). Revista Brasileira de Botânica 23: 1-11.

Trockenbrodt, M. 1990. Survey and discussion of the terminology used in bark anatomy. IAWA Bulletin 11: 141-166. 